\title{
What Do Pupils Laugh at? Content Analysis of Jokes
}

\author{
Loudova Irena ${ }^{1, a}$, Prikrylova Katarína ${ }^{1, b}$, Kudrnova Eva ${ }^{1, c}$ and Adam Trejbal ${ }^{1, d}$ \\ ${ }^{1}$ University of Hradec Králové, Faculty of Education, Department of Pedagogy and Psychology, \\ Rokitanského 62, 50003 Hradec Králové, Czech Republic
}

\author{
airena.loudova@uhk.cz, 'batarina.prikrylova@uhk.cz, 'eva.kudrnova@uhk.cz, \\ dadam.trejbal@uhk.cz
}

\begin{abstract}
Keywords: early adolescence, joke, content analysis of the joke, a hero of the joke
Abstract. The joke is a ticket to the culture of adolescents. Humorous situations play a central role in the socialization of adolescents. The research material is a collection of selected jokes ( 3 of the funniest ones) coming from 181 pupils at the age of early adolescence and is subjected to qualitative content analysis with an inclination to heuristic processing. It identifies the heroes of the jokes and describes the breach of their integrity in a sense of deviation from their normal life roles, which is a certain prerequisite to becoming a hero of the joke. Another characteristic feature of such heroes is commonly known as dehonestation and also relation to a prospective hero in a supporting role. The study describes at least two semantic plans of each joke in relation to reality. The key concept of the joke is a punchline and one of the objectives was to determine what it produces. If humor is a tool by which members of the peer culture cope with the content of adult culture, there is one of the possibilities to learn at least to some extent about the content of the early adolescent pupils' culture. The study, by its results, clearly delineates its propositions of the primary sources, as well as theories of contemporary authors and contributes to the understanding of a not easily accessible research field.
\end{abstract}

\section{Culture of Early Adolescent Pupils, Socialization}

To be funny means to have an ability to be accepted by a certain group of people and acquire a social status, which in the time of early adolescence, closely relates to the formation of identity. Ziv [1] talks about humor as a ticket to a group. Pupils are aware of "a playful framework" [2], how telling jokes feels different from serious reality which guarantees a separation of these two areas. It includes various content taboos, sensitive and controversial themes and through reactions of listeners, the pupils verify their place in the group. They also verify the boundaries of so called "playful frameworks" and acceptability of the content of the jokes with the audience. The content is mostly about the culture of adults and their ability to deal with taboo content shows a certain level of proficiency. Smolík [3], describes that appreciation by peers makes the pupils feel significant and it strengthens their own positions in the group. A joke as a form of humor is intellectual. The production of humor is developing as we mature, while involvement in games is waning. Humor and a game is described by Šed'ová [2] as phenomena which are not identical, despite overlaps, and fulfill a similar function within the peer group.

\section{A Joke}

A joke that is still passed in the same form, is called by Martin [4] a "canned joke" (or a "conserved joke"). The essence of a "conserved joke" is that it has a clear punchline. The point itself is a cognitive structure (it has its own structure) and demands a cognitive requirement from the recipient of the joke - they must find and understand the inconsistency of the contextual humor [5], at the same time they must be able to identify the socio-cultural meanings that the joke shows and be also empathetic [2 6].

A prerequisite for understanding the joke and the punchline is knowledge of symbolism and general skills related to the understanding of contexts and knowledge through symbols. A representative of the post-analytic philosophy, Goodman [7], bases communicability and relationships of the language and non-language symbolic system on a certain distinctiveness, i.e., how dense or articulated these systems are. The interpretation of the joke is an activity of a recipient 
and it depends on their cultural and communication skills in the frame of social interaction and further on the ability of empathy and interpretation, i. e we call one of the components a sense of humor. It is a means of social reflection based on the knowledge of the combination of contexts where "ridiculous effect is caused by oscillations between two poles of meaning and switching between these two contexts" [2]. When Freud expresses the essence [8] of a joke, he deals mainly with short, concise events during the conversation and deals with the conditions of its origin with the help of a dream model. In the description of the concept of a joke, Freud refers to [8] philosopher K. Fischer, who uses characteristic features as a playful judgment and playful contemplation of things. In Freud's interpretation it is rarely a premeditated joke, mastered by heart, if so, it's a part of the conversation. He differentiates a joke which is created or told by "the joker". For Freud, who describes jokes as a playful framework analogically, calls the same phenomenon as a frame of comicality [11].

\section{The Aim of the Research}

The project is based on a long-term research plan formulated in cooperation with the CPV UHK with the intention of transferability of achieved results into other related research studies and eventually into educational practice. During the phase of collecting information about categorization, typology, or a content analysis of jokes we found that conventional categorization and typology are insufficient. The available professional typology lacked details and are unsystematic for the sake of our objectives. The research problem was supposed to lead to the recognition of the given pupil's culture through jokes. Through a solution of a methodological problem there was created a structure of a content analysis of jokes. The basic question of this research is: What do pupils laugh at? The sub-questions are: Which environment generates meaningful plans of joke content? Who are considered the heroes of jokes? What are the punchlines of jokes that circulate among students? Methodological question: how can we most effectively build a range of key codes for content analysis jokes?

\section{Procedure}

From the forms of humor [4]: joke, spontaneous conversational humor and unintended humor, jokes were chosen as the best form because they are the most transparent and conclusive. We contacted a representative of elementary and secondary school of the Hradec Králové region with a request for the pupils to send their three best jokes via e-mail. We proceeded from the fact that communication via Internet allows courageous response and we supported this because of the opportunities to stay anonymous. The intention was to prevent censorship and self-censorship and get a set of best pupil jokes, and learn as much as possible about pupil's culture from the "inside", because, as mentioned [9], especially in the presence of investigating adults, students speak very little, incompletely or inaccurately.

The jokes were obtained during the period of one month in the quantity of $\mathrm{N}=488$ from 181 students (102 girls, 51 boys, 28 did not state sex). The sample consisted of 332 verbal jokes, 77 were excluded for the following reasons (some pupils belonged to a different age group, it was not a joke, or it was a description of situational and conversation humor). Data specification: a set of analyzed jokes (re)produced by pupils, recipients are pupils, it is the intended humor, portable and universally comprehensible, and prepared in advance. Standalone jokes are not told in the context of a situation or conversation.

\section{Method}

Focus and the nature of the research problem led to the choice of qualitative-quantitative content analysis of the data. The base was an unbiased conception of the phenomenological approach with the inclination to heuristic processing [10]. Data were analyzed using the software for ATLAS.ti. The process of research adheres to the grounded theory only partially, due to the nature of the research material. In terms of the starting point of the research the probe is in accordance with the method of 
grounded theory in the way that the sample of students who told us jokes is defined by the population as peer culture in a specific environment.

However - in comparison with the procedures of grounded theory - the goal of our research was not atypical theory as a story consisting of a three-level coding, but the theory of an inclination to a typology that is not typical for the pedagogical teaching. Conceptualization of jokes led us to establish the set of categories of jokes. Each joke expressed by words was encoded. A set of basic categories was established: hero, the defining plan, the point, and rules within an institution. In this study, the jokes were analyzed only in light of the "hero". Focus was on the frequency, sequence, and levels of certain quality of the "hero" criteria.

\section{Results}

Who are the heroes of jokes? We marked the hero of the joke, the one to whom we laugh at. For the specification, the descriptive terms such stereotypes were used. The heroes of jokes see in Table 1.

\section{Table 1 The Heroes of Jokes}

\begin{tabular}{l|l} 
Hero & Rel. Frequency (\%) \\
\hline The members of ethnic and religious minorities (mostly jews and gypsies) & 12.6 \\
Animal & 7.7 \\
Baby & 6.6 \\
The Czech citizen + narrator of the joke & 6.2 \\
Folk & 5.5 \\
A man & 5.2 \\
A blonde woman & 4.9 \\
Public figure & 4.6 \\
Neutral person (e. g. Someone) & 4.6 \\
A woman & 4.3 \\
Authority & 4.0 \\
Others & 33,8
\end{tabular}

To specify the hero in closer detail, we focused on two indicators that define him/her. They are: violation of integrity and dehonestation. In the integrity violation of the hero, we were interested in, how is the hero deviated from their usual role in life.

What drew their attention? At $26.2 \%$, it was impossible to describe the integrity violation or there was simply none. $6.1 \%$ points to unhappiness, $5.1 \%$ bad boy reputation, the same percentage shows their prejudices. At 3.6\% deals with disease or disability, at 3.2\% shows hatred and envy, and the same percentage shows domination. Another 44 terms are not possible to categorize even in related clusters.

The third identifier of the hero of the joke is dehonestation, therefore, what in ordinary reality insults, slanders and dishonors the hero, which then leads to the fact that the hero becomes a joke. In the case of $24.2 \%$ of cases we cannot talk about any dishonestation of the hero. $14.7 \%$ indicates the stereotype of an idiotic person, $10.1 \%$ stereotype of a dummy, $5.9 \%$ for death under humiliating circumstances, $5.6 \%$ on the stereotype of dumb beauties $4.6 \%$ on the stereotype of the poor. $3.9 \%$ of heroes of jokes are dishonored by the stereotype needy, poor fellows $3.6 \%$ are poor souls and $3.3 \%$ belong to the category of exotic creatures.

These results confirm partially the assumption that people laugh at groups with which they do not identify, and those which they direct negative emotions [2]. Our adolescents perceive themselves as the hero of the joke at least $6.2 \%$ of the jokes. This occurrence represents a relatively significant portion of jokes, which are the target of laughter of the storytellers themselves. Heroes, against whom the negative emotion behavior is evident, cannot be confirmed, because they represent forms of insults which show rather regrettable indicators. Overall, the negative emotions are reflected in the $11.4 \%$ of the indicators, such as: the stereotype of fury, brute, bitch, nuisance, spoiled pest, greedy 
person, bastard, halfwit, a murderer and a thief. These all do not create enough of a significant percentage to be able to confirm the above mentioned assumption. Eighty one jokes involve another character that is identified as the second hero. However, this hero is no longer the object of laughter. This is someone who somehow opposes the hero and his presence enhances the punchline. In $14.8 \%$, the company to the hero is made by an angry and surprised figure, in $9.8 \%$ it is a partner, in $7.4 \%$ it is the narrator of the joke, in $6.2 \%$ it is the parent. Thirty three terms indicate other heroes in a small representation. Jokes with a few heroes appear rarely.

\section{Conclusion}

The current state of the content analysis of jokes is worth continuing the research of several variants so far identified phenomena in various combinations, with the aim to better know the content of the jokes of our narrators with respect to quality, which form their identities [11]. Equally important and extensive is a theme of the structure of the joke. Each student subculture has its own specifics in sharing jokes, which is then projected to limit data collection, further to the methodology and logically then to the interpretation of results. The first aim is to describe the joke in the best way and then humor for the widest possible spectrum of students, focusing on creative thinking and ingenuity. The research results will find their application in educational practice and will also contribute to intercultural communication [12]. Using the existing results in the area of the point of the joke, it will be contributive and interesting to make a measurement of moral judgment. Defining a hero of the joke provides teachers with the knowledge of how to work with children of a wide range of identities. Teachers can work with the concepts of compassion and tolerance at a higher level.

\section{Acknowledgements}

This work was financially supported by the University of Hradec Králové Specific Research project no. 2101 "What do Children Laugh at? Analysis and Categorization of Humorous Stimuli in the Context of Early Adolescence".

\section{References}

[1] A. Ziv: The social function of humor in interpersonal relationships. Society, Vol. 47, Issue 1 (2010), p. 11-18.

[2] K. Šed’ová: Humor ve škole. Brno, Masarykova Univerzita (2013), p. 12, 19, 20, 31, 155.

[3] J. Smolík: Subkultury mládeže. Uvedení do problematiky. Praha, Grada (2010), p. 24.

[4] R. A. Martin: The Psychology of Humor. An Integrattive Approach. London, New York, Elsevier (2007), p. 12.

[5] S. Attardo, C. F: Hempelmann and S. DiMaio: Script oppositions and logical mechanism: modeling incongruities and their resolution. Humor, Vol. 11, Issue 3 (2002), p. 231-260.

[6] G.W. Alport: O povaze předsudkì. Praha, Prostor (2004).

[7] N. Goodman: Jazyky umění. Nástin teorie symboli̊. Praha, Academia (2007), p. 175.

[8] S. Freud: Vtip a jeho vztah $k$ nevědomí. Praha, Psychoanalytické nakladatelství J. Kocourek (2005), p. 113, 122.

[9] S. Štech: Co přinesl „obrat k dítěti“ a co naopak skryl? Pedagogika, Vol. LXVI, Issue 1 (2016), p. 73-82.

[10] J. Hendl: Kvalitativní výzkum. Praha, Portál (2005), p. 75.

[11] J. Havigová a E. Holečková: What Do Children Laugh At? Analysis Of Preschool Children's Humor. ICERI2015 Proceedings. Seville, Spain (2015), p. 2181-2189. 
[12] M. Levínská: Možnosti zvládání interkulturní komunikace. Případ českých Romů na české škole. In Bittnerová, D. (Ed.) Etnické komunity - Romové. Praha, FHS UK (2013), p. 113-131. 